\title{
The long-term survival of robotic lobectomy for non-small cell lung cancer: A multi-institutional study
}

\author{
Robert J. Cerfolio, MD, MBA, ${ }^{\mathrm{a}}$ Asem F. Ghanim, MD, ${ }^{\mathrm{a}}$ Mark Dylewski, MD, ${ }^{\mathrm{b}}$ Giulia Veronesi, MD, ${ }^{\mathrm{c}, \mathrm{d}}$ \\ Lorenzo Spaggiari, MD, ${ }^{\mathrm{d}}$ and Bernard J. Park, $\mathrm{MD}^{\mathrm{e}}$
}

\section{ABSTRACT}

Objective: Our objective is to report the world's largest series with the longest follow-up of robotic lobectomy for non-small cell lung cancer (NSCLC).

Methods: This was a multi-institutional retrospective review of a consecutive series of patients from 4 institutions' prospective robotic databases.

Results: There were 1339 patients (men 55\%, median age 68 years). The median operative time was 136 minutes, median number of lymph nodes was 13 (5 N2 stations and $1 \mathrm{~N} 1)$, median blood loss was $50 \mathrm{cc}$, and $4(0.005 \%)$ patients received intraoperative transfusions. Conversions occurred in 116 patients $(9 \%)$ and for bleeding in $24(2 \%)$. Median length of stay was 3 days. Major morbidity occurred in $8 \%$. The 30 -day and 90 -day operative mortality was $0.2 \%$ and $0.5 \%$, respectively. Follow-up was complete in $99 \%$ of patients with a median follow-up of 30 months (range 1-154 months). The 5-year stage-specific survival was: $83 \%$ for the 672 patients with stage IA NSCLC, $77 \%$ for the 281 patients with stage IB, $68 \%$ for the 118 patients with stage IIA, $70 \%$ for 99 patients with IIB, $62 \%$ for 143 patients with stage IIIA (122 had N2 disease, $73 \%$ ), and $31 \%$ for 8 patients with stage IIIB (none had N3 disease). The cumulative incidence of metastatic NSCLC was 15\% (128 patients, 95\% confidence interval, 13\%$18 \%)$. The cumulative incidence of local recurrence in the ipsilateral operated chest was $3 \%$ only (26 patients, $95 \%$ confidence interval, $2 \%-5 \%$ ).

Conclusions: The oncologic results of robotic lobectomy for NSCLC are promising, especially for patients with pathologic N2 disease. However, further followup and studies are needed. (J Thorac Cardiovasc Surg 2018;155:778-86)

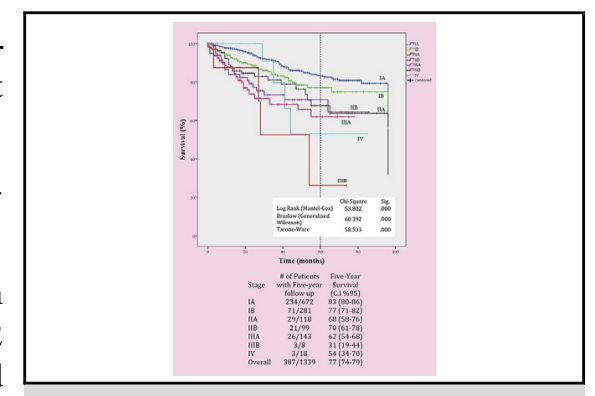

Stage-specific survival for non-small cell lung cancer after robotic lobectomy.

\section{Central Message}

Our objective is to report the world's largest series with the longest follow-up of robotic lobectomy for non-small cell lung cancer.

\section{Perspective}

The mid-term oncologic results of robotic lobectomy for non-small cell lung cancer are quite promising, especially for patients with pathologic N2 disease.

See Editorial Commentary page 787

See Editorial page 777.
Lobectomy for non-small cell lung cancer (NSCLC) is best performed via minimally invasive techniques such as videoassisted thoracoscopy (VATS) and robotic surgery. ${ }^{1}$ The latter has been shown to be safe and effective for pulmonary lobectomy for lung cancer with intraoperative and shortterm postoperative metrics such as operative time, blood

\footnotetext{
From the a Division of Thoracic Surgery, University of Alabama - Birmingham, Birmingham, Ala; ${ }^{b}$ Division of Thoracic Surgery, Baptist Health of South Florida, Miami, Fla; ${ }^{\mathrm{c} D i v i s i o n}$ of Thoracic Surgery, Istituto Clinico Humanitas Cancer Center, Rozzano; ${ }^{\mathrm{d}}$ Istituto Europeo Di Oncologia, Milan, Italy; and ${ }^{\mathrm{e}}$ Thoracic Service, Department of Surgery, Memorial Sloan Kettering Cancer Center, New York, NY. Received for publication March 30, 2017; revisions received Aug 23, 2017; accepted for publication Sept 2, 2017; available ahead of print Oct 12, 2017.

Address for reprints: Robert J. Cerfolio, MD, MBA, Professor of Surgery, Director of Lung Cancer Service Line Langone Medical Center New York University (NYU),

Chief of Clinical Division of Cardiothoracic Surgery, Department of Surgery, 550

First Ave, New York, NY 10016 (E-mail: robert.cerfolio@nyu.org).

$0022-5223 / \$ 36.00$

Copyright (c) 2017 by The American Association for Thoracic Surgery

https://doi.org/10.1016/j.jtcvs.2017.09.016
}

loss, conversions rates, ability to achieve R0 resection, length of stay, learning curve for surgeons, and postoperative pain. ${ }^{2-6}$

Some reports suggest that robotic lobectomy may boast improved lymph node resection and less blood loss than other forms of minimally invasive surgery. ${ }^{7}$ However, other reports suggest there is no advantage. ${ }^{8}$ Surgeons, insurers, Centers of Medicare and Medicaid Services, and even the Society of Thoracic Surgeons Database judge the quality of lobectomy via a strikingly myopic lens of 30- and 90day mortality. The true value of an operation, if for

\section{Scanning this $Q R$ code will take} you to a procedural video. 


\section{Abbreviations and Acronyms \\ $\mathrm{CT}=$ computed tomography \\ EBUS $=$ endobronchial ultrasound \\ NSCLC $=$ non-small cell lung cancer \\ PET = positron emission tomography \\ $\mathrm{UAB}=$ University of Alabama at Birmingham \\ VATS $=$ video-assisted thoracoscopy}

reconstructive reasons, is its durability and the quality of life it offers over time compared with other treatment options and their costs. If the operation is performed for cancer, then the true value is the stage-specific 5-year survival rate and/or local recurrence rate compared with other treatment options and their cost. This may be the best metric of value over time. Yet, it is rarely mentioned as a surrogate for quality, and, interestingly, there are very few reports on the 5 -year survival of any minimally invasive series that is not on patients with stage I cancer.

Robotic thoracic surgery is in its infancy, and there have been few to no reports on this important metric. Park and colleagues in $2012^{9}$ reported survival data in a series of 325 patients with a median follow up of 27 months (27/ 176 with stage IA, 6/72 with stage IB, and 5/54 with stage II had a follow-up of 5 years). However, only 38 of the 325 $(12 \%)$ patients had actual 5-year survival data. The goal of this study is to provide an update on that experience, as many of those patients are in this study and we have added more patients to the report. As we collect more data, we obtain a more accurate view over time. This is to our knowledge the largest series of robotic lobectomy and the series with the longest median follow-up of patients who had completely resected NSCLC via robotic lobectomy. This enhances our understanding of the value of robotic lung cancer surgery.

\section{METHODS}

This is a multicenter cohort study that used prospective databases from the thoracic surgery divisions of 4 institutions: (1) The University of Alabama at Birmingham (UAB) in Birmingham, Alabama; (2) The Miami Cancer Institute: Baptist Health of South Florida in South Miami, Florida; (3) The Istituto Clinico Humanitas Cancer Center, Istituto Europeo Di Oncologia in Milan, Italy; and (4) The Memorial Sloan Kettering Cancer Center in New York, New York. The study was approved by the institutional review board of each institution, and a data transfer agreement was made to UAB. All data regarding preoperative characteristics, operative details, hospital course, pathologic findings, and postoperative follow-up were recorded prospectively at the individual institutions and sent to UAB for data entry and analysis. The primary endpoint of this study was the 5-year survival of the patients.

Definitions were the same at each institution, and operative time was defined as the time from the first skin incision was made until the last skin incision was closed. The seventh edition of the International American Joint Commission on Cancer was used throughout the paper. Major morbidity was defined with the Society of Thoracic Surgeons General Thoracic Surgery Database Report 2012. ${ }^{10}$ Major complications included pneumonia, acute respiratory distress syndrome, bronchopleural fistula, pulmonary embolus, initial ventilator support $>48$ hours, reintubation, tracheostomy, myocardial infarction, and unexpected return to the operating room. Complications such as hemorrhage, pulmonary edema, atelectasis, stroke, kidney failure, and infection of the chest wound also were considered as major complications. Minor complications included atrial fibrillation, prolonged air leak, chylothorax, and readmission. The pathology that was considered "other" included clear cell, unspecified, poorly differentiated large cell carcinoma, and atypical carcinoid tumors.

\section{Inclusion Criteria}

Eligible patients were those with biopsy-proven or suspected primary NSCLC who underwent operation with the intent to cure and with the intent to perform it robotically. Patients who underwent lobectomy that was performed initially via VATS or open were excluded from this study unless the operation was started off robotically and converted. Clinical staging was performed with computed tomography (CT) of the chest and integrated whole-body positron emission tomography (PET) in all patients. In addition, staging via mediastinoscopy and/or endobronchial ultrasound (EBUS) was used liberally in selected patient groups, such as those with suggested N2 or N1 disease, those with synchronous tumors in different sides of the chest, or those with tumors larger than $5 \mathrm{~cm}$ (even if clinically node negative). This study included patients clinically staged as stage IV secondary to the presence of a second lung nodule seen concurrently in the opposite side of the chest. These patients were pathologically staged as stage IV if they harbored the same pathology in the 2 resected lung nodules but were treated as if they had synchronous staged tumors if their mediastinum and hilum had lymph nodes that were pathologically negative. In addition, stage III advanced disease that was resected also was included in this study. The different operative techniques used by the individual surgeons has been described previously at length. ${ }^{11-13}$

\section{Exclusion Criteria}

Patients who had benign disease, small cell lung cancer, or metastatic lesions resected via robotic lobectomy were excluded from this study. Furthermore, patients who underwent segmentectomy also were excluded.

\section{Surveillance and Follow-up}

Postoperative surveillance was similar at each institution and consisted, in general, of a CT scan of the chest and upper abdomen at 3- to 6-month intervals with appropriate scans if suspicious lesions were detected. $\mathrm{Pa}$ tients also had integrated PET/CT scans if CT scan suggested a new lesion greater than $8 \mathrm{~mm}$ but PET was not implemented routinely as part of the postoperative surveillance program. Follow-up data were obtained via medical records, letters, and/or telephone calls to the following physicians. Patient consent was obtained for inclusion in the individual centers' prospective database but was not obtained specifically for this particular study. The institutional review board number for this study at the reporting center (UAB) was X150223002.

\section{Statistics}

Data was stored in an Excel database (Microsoft, Redmond, Wash). Descriptive and Kaplan-Meier survival analysis was done with IBM SPSS Statistics for Windows, Version 24.0 (IBM Corp, Armonk, NY). Cumulative Incidence was calculated with NCSS 11 Statistical Software (NCSS, LLC, Kaysville, Utah).

A robotic right upper lobectomy is shown in Video 1.

\section{RESULTS}

From 2003 through 2016, 1339 patients underwent intended robotic lobectomy for primary NSCLC with intent to cure. Table 1 depicts the various patient numbers, 


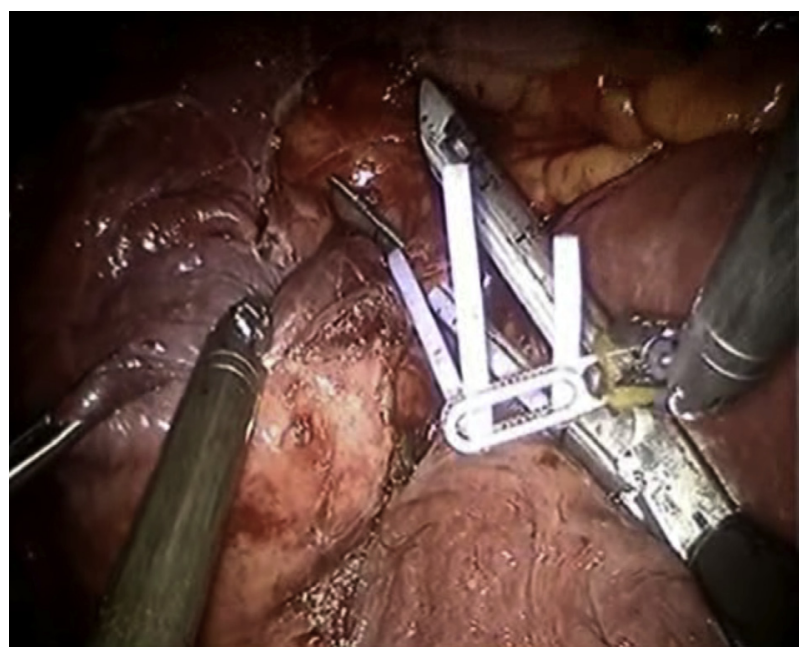

VIDEO 1. Video of a robotic right upper lobectomy. Video available at: http://www.jtcvsonline.org/article/S0022-5223(17)31919-0/fulltext.

characteristics, and dates of inclusion from each institution. Table 2 shows the preoperative disease characteristics and short-term outcomes (estimated blood loss, conversions, length of stay, and pathology). R0 resection was obtained in all but 3 patients who had microscopic disease noted on final pathology but was thought to be R0 at the time of the operation.

Follow-up was complete in $99 \%$ of patients, and only $1 \%$ were lost to follow-up. The median length of followup is currently 30 months. Figure 1 depicts the overall 5year curve for the various stages of NSCLC along with the number of patients actually alive in that time frame. Figure 2 shows the survival based on the specific stages with the number of patients at risk at each time interval. The total number of recurrence was 128 patients (cumulative incidence $=15 \% ; 95 \%$ confidence interval, $13 \%$ -
$18 \%$ ) with a median disease-free interval of 16 months (range 1-82). Local recurrence occurred in 26 patients (cumulative incidence $=3 \% ; 95 \%$ confidence interval, $2 \%-5 \%$ ).

There were 122 patients with pathologic-proven N2 disease; 31 were proven before lobectomy via mediastinal lymph node sampling, and 91 had pathologic N2 disease after resection. Of the 31 patients with preoperative proven N2 disease, $27(87 \%)$ underwent neoadjuvant chemotherapy before resection and 4 had neoadjuvant chemoand radiotherapy. Their 5-year survival was $51 \%$. Of the 91 patients with pathologic $\mathrm{N} 2$ disease who did not have neoadjuvant treatment, $70(77 \%)$ underwent adjuvant chemotherapy and 10 had adjuvant chemo- and radiotherapy. Their 5-year survival was $66 \%$.

\section{DISCUSSION}

During the past decade, robotic thoracic surgery for lung cancer has been shown to be safe and associated with several promising short-term quality metrics for cancer surgery, such as operative time, estimated blood loss, number of total lymph nodes resected and number of $\mathrm{N} 2$ and N1 stations assessed, conversion rates to thoracotomy, transfusions rate, R0 resection rates, length of stay, and readmission rates. ${ }^{2-6}$ Several reports suggest benefits, including improved lymph node harvesting and less median blood loss than other minimally invasive techniques. ${ }^{7}$

One controversial finding concerns the improved lymph node resection that is often cited in the robotic literature. Rajaram and colleagues ${ }^{8}$ found no improvement in the number of lymph nodes resected. Lymph node resection may be more operator dependent then platform (video-assisted vs robotic vs open) dependent. Kent and colleagues $^{1}$ suggested a lower mortality with robotic

TABLE 1. Institutional numbers and patient characteristics

\begin{tabular}{|c|c|c|c|c|c|}
\hline & UAB & Baptist Health South Florida & IEO & MSKCC & Overall \\
\hline Patients, $\mathrm{n}$ & 438 & 319 & 154 & 428 & 1339 \\
\hline Time frame & $2 / 2010$ to $6 / 2016$ & $1 / 2007$ to $8 / 2014$ & $11 / 2006$ to $11 / 2013$ & $1 / 2003$ to $4 / 2016$ & $1 / 2003$ to $6 / 2016$ \\
\hline Time period, mo & 77 & 92 & 85 & 161 & 163 \\
\hline $\begin{array}{l}\text { Median } \\
\text { follow-up data, mo }\end{array}$ & 30 & 29 & 45 & 30 & 30 \\
\hline Age, $y$, median (range) & $69(33-95)$ & $68(20-92)$ & $63(39-78)$ & $69(21-87)$ & $68(20-95)$ \\
\hline \multicolumn{6}{|l|}{ Sex, $\%$} \\
\hline Male & 48 & 46 & 71 & 42 & 55 \\
\hline Female & 52 & 54 & 29 & 58 & 45 \\
\hline Smoker, \% & 82 & N/A & 86 & N/A & 83 \\
\hline \multicolumn{6}{|l|}{ Preoperative PFTs } \\
\hline FEV1, \% predicted (range) & $84(28-167)$ & $81(19-123)$ & $92(49-149)$ & $93(34-171)$ & 85 \\
\hline DLCO, $\%$ predicted (range) & $74(10-154)$ & N/A & N/A & N/A & 74 \\
\hline
\end{tabular}

$U A B$, University of Alabama at Birmingham; IEO, Istituto Europeo Di Oncologia; $M S K C C$, Memorial Sloan Kettering Cancer Center; N/A, not available; $P F T$, pulmonary function test; $F E V I$, forced expiratory volume in one second; $D L C O$, diffusing capacity of the lungs for carbon monoxide. 
TABLE 2. Preoperative disease characteristics and operative outcomes

\begin{tabular}{|c|c|c|c|c|c|}
\hline Category & UAB & Baptist Health of South Florida & IEO & MSKCC & Overall \\
\hline Patients, $\mathrm{n}$ & 438 & 319 & 154 & 428 & 1339 \\
\hline \multicolumn{6}{|l|}{ Primary tumor location, $\%$} \\
\hline RUL & 40 & 32 & 37 & 38 & 37 \\
\hline RML & 8 & 8 & 8 & 6 & 7 \\
\hline RLL & 18 & 17 & 14 & 20 & 18 \\
\hline LUL & 16 & 26 & 25 & 21 & 21 \\
\hline LLL & 16 & 14 & 16 & 14 & 15 \\
\hline Others & 2 & 3 & 0 & 1 & 2 \\
\hline \multicolumn{6}{|l|}{ Histology, $\%$} \\
\hline Adenocarcinoma & 60 & 60 & 81 & 80 & 69 \\
\hline Squamous cell carcinoma & 27 & 18 & 12 & 10 & 18 \\
\hline Other & 13 & 22 & 7 & 10 & 14 \\
\hline \multicolumn{6}{|l|}{ Pathologic stage, $\% *$} \\
\hline IA & 49 & 47 & 56 & 52 & 50 \\
\hline IB & 20 & 24 & 23 & 19 & 21 \\
\hline IIA & 9 & 6 & 6 & 11 & 8 \\
\hline IIB & 9 & 11 & 3 & 5 & 8 \\
\hline IIIA & 10 & 11 & 9 & 12 & 11 \\
\hline IIIB & 1 & 1 & 0 & 0 & 1 \\
\hline IV & 2 & 0 & 3 & 1 & 1 \\
\hline Tumor size, mm, median (range) & $30(4-188)$ & $22(4-250)$ & $19(2-80)$ & $21(1-200)$ & $21(2-250)$ \\
\hline No. of N1, N2 lymph node stations, median (range) & $8(7-10)$ & $6(4-9)$ & N/A & $5(4-9)$ & $6(4-10)$ \\
\hline No. of N1, N2 lymph nodes, median (range) & $19(11-42)$ & $10(5-40)$ & $15(7-35)$ & $16(7-48)$ & $13(0548)$ \\
\hline Operative time, min, median (range) & $129(43-348)$ & $133(40-300)$ & $195(93-411)$ & $182(38-394)$ & $136(38-411)$ \\
\hline Estimated blood loss, mL, median (range) & $20(10-800)$ & $75(20-1000)$ & N/A & N/A & $50(10-1000)$ \\
\hline Blood transfusion, $\mathrm{n}$ & 1 & 3 & N/A & N/A & 4 \\
\hline Conversion to thoracotomy, total, n (\%) & $41(9)$ & $12(4)$ & $18(12)$ & $45(11)$ & $116(9)$ \\
\hline Bleeding, $\mathrm{n}(\%)$ & $13(3)$ & $3(1)$ & $4(3)$ & $4(1)$ & $24(2)$ \\
\hline Length of stay, d, median (range) $\dagger$ & $3(1-41)$ & $3(1-86)$ & $5(3-73)$ & $4(1-35)$ & $3(1-86)$ \\
\hline \multicolumn{6}{|l|}{ Complications, \% } \\
\hline None & 84 & 74 & 71 & 72 & 76 \\
\hline Minor & 10 & 19 & 25 & 18 & 16 \\
\hline Major & 6 & 8 & 4 & 10 & 8 \\
\hline
\end{tabular}

In this study, stage IIIA included a highly selected group of patients who had a single station N2 disease. Stage IIIB included 8 patients who were clinically staged as T4N2 who had multiple pulmonary nodules found in different ipsilateral lung lobes. Stage IV included 18 patients with multiple nodules found in the contralateral chest who had no concurrent nodal disease and which could have been separate primaries. UAB, University of Alabama at Birmingham; IEO, Istituto Europeo Di Oncologia; $M S K C C$, Memorial Sloan Kettering Cancer Center; $R U L$, right upper lob; $R M L$, right middle lobe; $R L L$, right lower lobe; $L U L$, left upper lobe; $L L L$, left lower lobe; $N / A$, not available. *According to the American Joint Committee on Cancer (Seventh Edition): Lung Cancer Staging. †Length of stay considers any hospital stay less than 24 hours as 1 day.

lobectomy in a national database study on more than 33,000 patients. However, there are many disadvantages of robotic surgery, some of which include the initial capital and operational cost as well as the training required. There is also a learning curve when starting something new, during which quality can suffer and operating efficiency suffers.

Quality is defined by the mathematical equation: value divided by cost. The quality of an operation has been viewed myopically via 30- and 90-day metrics by insurance companies and hospitals. The true value of an expensive purchase is its durability and how it measures over time and how much money it might save over time-this should apply to an operation as well. There have been few reports that show perhaps the most important metric of quality for cancer surgery-long-term survival and recurrence rates. If something is going to cost more up front, it needs to provide enhanced value over time. Therefore, a cost analysis is a complicated but necessary part of any study on quality. Cost was not a goal of this study and therefore neither it nor quality is calculated. It would be difficult to do, given the different health care systems and varied costs in this multicountry study. However, if done, terms must be defined carefully prestudy, then cost must factor in the cost savings of reducing cancer recurrence as well as the added costs of treating more patients with recurrent cancer. 


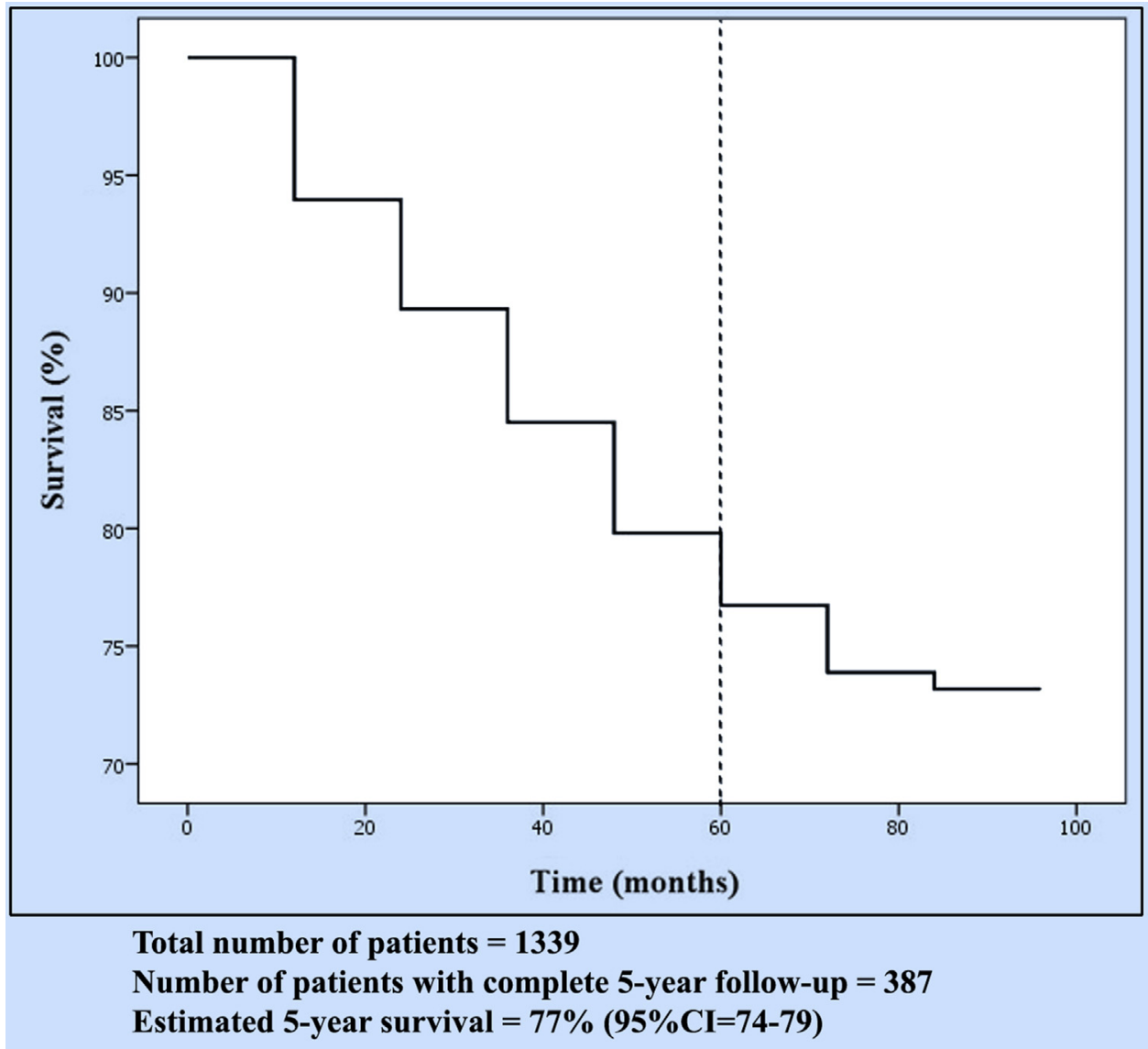

FIGURE 1. Overall survival for non-small cell lung cancer after robotic lobectomy. $C I$, Confidence interval.

In this work, we show an impressive stage-specific survival of patients with completely resected NSCLC. Table $3^{9,14-18}$ compares our results with several other large series that reported stage-specific survival for VATS or thoracotomy. We searched PubMed and Google Scholar extensively to find more studies that report the 5-year overall and stage-specific survival for their patients. It is worthy to note that the Japanese literature was excluded because of the large numbers of node-negative bronchioloalveolar component, lepidic, adenocarcinoma, and ground-glass opacity nodules.

It may be best to compare our survival data with that reported by Goldstraw and colleagues, ${ }^{19}$ who reported the 5year stage-specific actual survival according to the sixth edition of the International Association of the Study of Lung Cancer when they proposed the seventh TNM classification (Table 4). The work by Goldstraw and colleagues ${ }^{19}$ is a multi-institutional, multinational study that collected data from 46 sources from 19 countries. They had 100\% 5-year follow-up data for 67,725 patients with NSCLC treated by all modalities between 1990 and 2000 .

As shown, the survival for patients who underwent robotic resection is favorable, but caution must be stressed. The trend toward a decreasing survival rate as patients are followed longer over time is seen in our series when compared with the 2012 series by Park and colleagues, ${ }^{9}$ which included many of the same patients in this study. In that earlier report by Park and colleagues, only $12 \%$ of patients were actually 5 years out from surgery. This followup series has $29 \%$ of patients that have actual 5 years or more follow-up and the overall survival has fallen. This is commonly seen, and thus extreme caution must be warranted until further follow-up of these patients is obtained.

One possible explanation of the improved survival rate for minimally invasive operations compared with those performed via thoracotomy may be secondary to reduction of an immunocompromised state and lower cytokines. Flores and colleagues ${ }^{20}$ showed a lower systemic rate (solid-organ metastases) of NSCLC recurrence in patients who underwent resection via VATS compared with those who had a thoracotomy when matched stage for stage. One possible explanation of an increased survival rate of a robotic lobectomy is the ease of lymph node dissection, ${ }^{3}$ which leads to greater upstaging. ${ }^{21} \mathrm{~A}$ better $\mathrm{N} 1$ as well as $\mathrm{N} 2$ lymph node dissection may lead better staging and a greater chance of adjuvant chemotherapy.

Special discussion is warranted for our high reported survival for those with pathologic resected N2 disease. These 


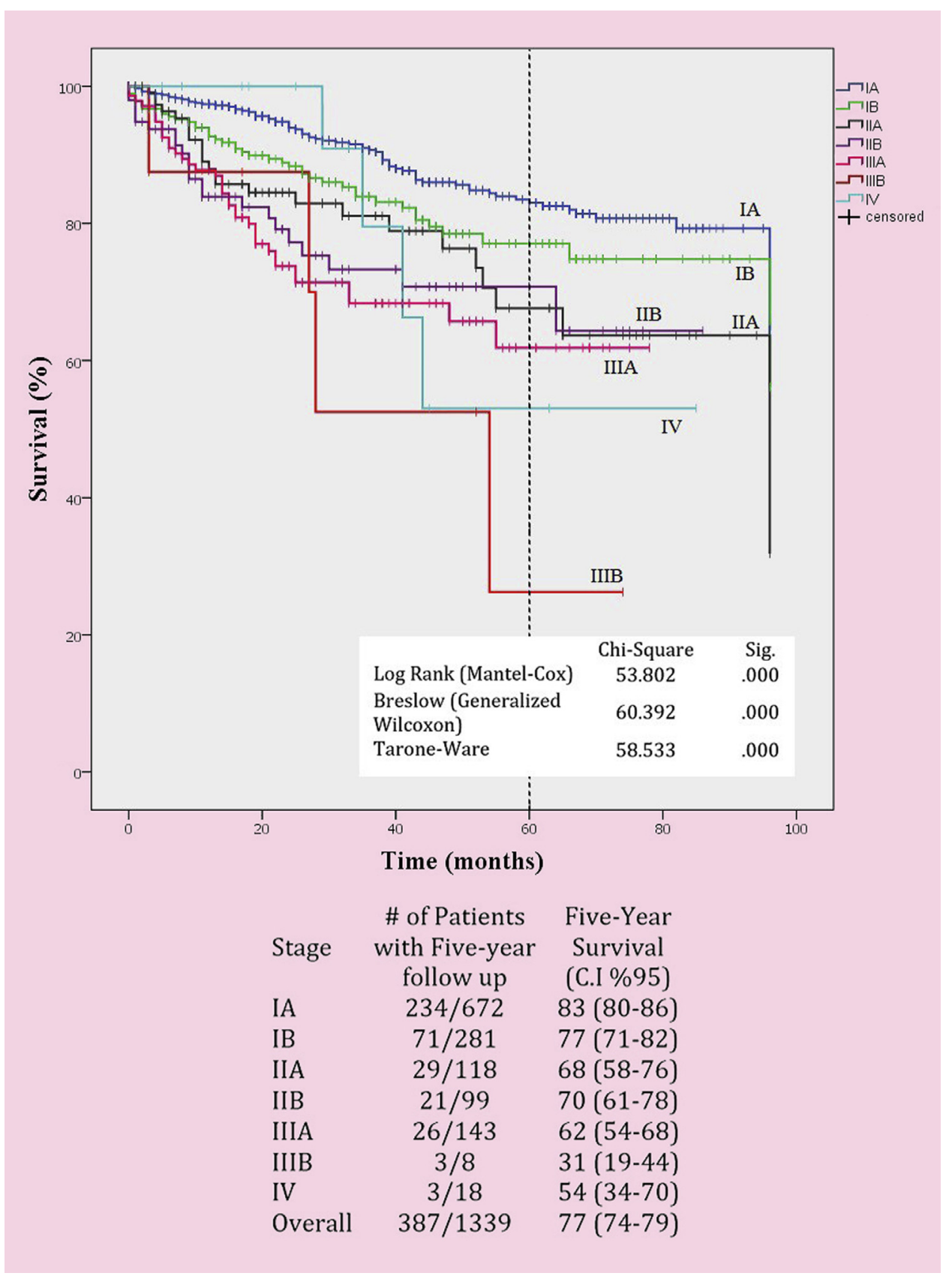

FIGURE 2. Stage-specific survival for non-small cell lung cancer after robotic lobectomy. $C I$, Confidence interval.

results may be and probably are secondary to the favorable set of patients with pathologic N2 disease reported in this series. Most had only single-station N2 disease. In addition, the centers in this study are highly experienced cancer centers that liberally use EBUS and mediastinoscopy before resection, as described in our Methods section. Those with biopsy-proven $\mathrm{N} 2$ disease before resection underwent neoadjuvant chemotherapy, as shown in the results section, and thus are a highly selected group of patients. Of note is the 18 patients with pathologic stage IV disease; all of these patients had hilar and mediastinal N1 and N2 node-negative disease on clinical staging by EBUS and/or mediastinoscopy. They all underwent resection and had similar pathology in both lungs, so by definition were called M1, but of course they could have represented synchronous primaries. However, their survival is only $54 \%$, which is much less than our IA and IB stages survival. Further follow-up is needed and DNA and genetic testing may in the future help identify synchronous primaries from true M1 metastatic deposits.

In addition, all surgeons in this study use complete thoracic lymphadenectomy and not lymph node sampling. 
TABLE 3. Robotic lobectomy compared with published VATS and thoracotomy 5-year survival

\begin{tabular}{|c|c|c|c|c|c|c|c|c|c|c|}
\hline \multirow{2}{*}{$\frac{\text { Author/year }}{\text { Type of operation }}$} & \multicolumn{2}{|c|}{$\begin{array}{c}\text { Thomas and } \\
\text { colleagues, } \text { 2002 }^{14}\end{array}$} & \multirow{2}{*}{$\begin{array}{c}\begin{array}{c}\text { Walker and } \\
\text { colleagues, } \\
\mathbf{2 0 0 3}^{15 *}\end{array} \\
\text { VATS }\end{array}$} & \multirow{2}{*}{$\begin{array}{l}\text { Yildizeli and } \\
\text { colleagues, } \\
2007^{16 *} \\
\text { Thoracotomy }\end{array}$} & \multicolumn{2}{|c|}{$\begin{array}{c}\text { Flores and } \\
\text { colleagues, } 2009^{17}\end{array}$} & \multicolumn{2}{|c|}{$\begin{array}{c}\text { Lee and } \\
\text { colleagues, } 2013^{18 *} *\end{array}$} & \multirow{2}{*}{$\begin{array}{c}\begin{array}{c}\text { Park and } \\
\text { colleagues, } \\
\mathbf{2 0 1 2}^{9}\end{array} \\
\text { Robotic }\end{array}$} & \multirow{2}{*}{$\begin{array}{c}\begin{array}{c}\text { Cerfolio and } \\
\text { colleagues, } \\
\text { current } \\
\text { study, } 2017\end{array} \\
\text { Robotic }\end{array}$} \\
\hline & VATS & Thoracotomy & & & VATS & Thoracotomy & VATS & Thoracotomy & & \\
\hline $\begin{array}{r}\text { Total number } \\
\text { of patients }\end{array}$ & 110 & 405 & 158 & 218 & 398 & 343 & 208 & 208 & 325 & 1,339 \\
\hline Median F/U, mo & N/A & N/A & 38 (mean) & 79 & 28 & 28 & 36 & 36 & 27 & 30 \\
\hline $\begin{array}{l}\text { No. patients actually } \\
\text { alive at } 5 \text { y, n (\%) }\end{array}$ & $26(24)$ & $108(27)$ & N/A & N/A & $11(3)$ & $30(9)$ & $18(9)$ & $92(44)$ & $38(12)$ & 387 (29) \\
\hline $\begin{array}{l}\text { Percent overall } \\
\text { survival reported }\end{array}$ & 63 & 63 & N/A & 53 & 79 & 75 & 75 & 77 & 80 & 77 \\
\hline Stage IA & & & Stage I & Stage I & & & Stage I & Stage I & & \\
\hline No. patients & 50 & 97 & $\begin{array}{l}117 \text { (48 IA, } \\
70 \mathrm{IB})\end{array}$ & $\begin{array}{l}69 \text { (21 IA, } \\
48 \text { IB) }\end{array}$ & 260 & 213 & $\begin{array}{r}168 \text { (120 IA, } \\
48 \text { IB) }\end{array}$ & $\begin{array}{r}146 \text { (105 IA } \\
41 \text { IB })\end{array}$ & 176 & 672 \\
\hline $\begin{array}{l}\text { No. patients actually } \\
\text { alive at } 5 \mathrm{y}(\%)\end{array}$ & $11(22)$ & $31(32)$ & N/A & N/A & N/A & N/A & $16(10)$ & $75(51)$ & $27(15)$ & $234(35)$ \\
\hline $\begin{array}{l}\text { Percent survival } \\
\text { reported }\end{array}$ & 65 & 80 & 78 & 57 & N/A & N/A & 79 & 84 & 91 & 83 \\
\hline \multicolumn{11}{|l|}{ Stage IB } \\
\hline No. patients & 60 & 308 & N/A & N/A & 69 & 62 & N/A & N/A & 72 & 281 \\
\hline $\begin{array}{l}\text { No. patients actually } \\
\text { alive } 5 \text { y }(\%)\end{array}$ & $15(25)$ & $77(25)$ & N/A & N/A & N/A & N/A & N/A & N/A & $6(8)$ & $71(25)$ \\
\hline $\begin{array}{l}\text { Percent survival } \\
\text { reported }\end{array}$ & 61 & 58 & N/A & N/A & N/A & N/A & N/A & N/A & 88 & 77 \\
\hline Stage IIA & & & Stage II & Stage II & & & & & Stage II & \\
\hline No. patients & N/A & N/A & $\begin{array}{l}33 \text { (8 IIA, } \\
25 \text { IIB) }\end{array}$ & $\begin{array}{l}86 \text { (6 IIA, } \\
80 \text { IIB) }\end{array}$ & 19 & 17 & N/A & N/A & $\begin{array}{r}56 \text { (41 IIA, } \\
15 \text { IIB) }\end{array}$ & 118 \\
\hline $\begin{array}{l}\text { No. patients actually } \\
\text { alive } 5 \text { y }(\%)\end{array}$ & N/A & N/A & N/A & N/A & N/A & N/A & N/A & N/A & $5(9)$ & $29(25)$ \\
\hline $\begin{array}{l}\text { Percent survival } \\
\text { reported }\end{array}$ & N/A & N/A & 51 & 70 & N/A & N/A & N/A & N/A & 49 & 68 \\
\hline \multicolumn{11}{|l|}{ Stage IIB } \\
\hline No. patients & N/A & N/A & N/A & N/A & 12 & 15 & N/A & N/A & N/A & 99 \\
\hline $\begin{array}{l}\text { No. patients actually } \\
\text { alive } 5 \text { y }(\%)\end{array}$ & N/A & N/A & N/A & N/A & N/A & N/A & N/A & N/A & N/A & $21(21)$ \\
\hline $\begin{array}{l}\text { Percent survival } \\
\text { reported }\end{array}$ & N/A & N/A & N/A & N/A & N/A & N/A & N/A & N/A & N/A & 70 \\
\hline \multicolumn{11}{|l|}{ Stage IIIA } \\
\hline No. patients & N/A & N/A & 8 & N/A & 29 & 21 & N/A & N/A & 21 & 143 \\
\hline $\begin{array}{l}\text { No. patients actually } \\
\text { alive } 5 \text { y }(\%)\end{array}$ & N/A & N/A & N/A & N/A & N/A & N/A & N/A & N/A & N/A & $26(18)$ \\
\hline $\begin{array}{l}\text { Percent survival } \\
\text { reported }\end{array}$ & N/A & N/A & 29 & N/A & N/A & N/A & N/A & N/A & N/A & 62 \\
\hline
\end{tabular}

VATS, Video-assisted thoracoscopy; $F / U$, follow-up; $N / A$, not available. *These studies reported the estimated survival for stages I, II, and/or III as a whole.

This leads to better intraoperative staging during resection and more liberal discovery of $\mathrm{N} 2$ disease, which led to the use of adjuvant chemotherapy in $76 \%$ of these patients. All of these facts lead to improved survival of these patients. These factors, in addition to the robotic platform, may be at play for the high reported survival rate. Any retrospective series is laden with bias, especially one that is from 4 selected institutions.
There are several important weaknesses and limitations of this study. First, it is only from 4 highly-selected experienced lung cancer centers that also are experienced in robotic surgery. They have some of the highest volumes in the world for robotic surgery. Thus, these results may represent a sampling error that favors improved intraoperative results, less postoperative complications, and lower 30- and 90-day mortality rates. In addition, these centers are known to be centers 
TABLE 4. Comparing the estimated 5-year survival and median survival times between the current study and the TNM classification and IASLC

\begin{tabular}{lccr}
\hline Stage & IASLC sixth edition & IASLC seventh edition & Current study seventh \\
\hline IA $^{*}$ & $73 \%(119)$ & $73 \%(119)$ & $83 \%(80-86,142)$ \\
IB & $54 \%(70)$ & $58 \%(81)$ & $77 \%(71-82,132)$ \\
IIA & $48 \%(54)$ & $46 \%(49)$ & $68 \%(58-76,123)$ \\
IIB* & $38 \%(33)$ & $36 \%(31)$ & $70 \%(61-78,84)$ \\
IIIA* & $25 \%(23)$ & $24 \%(22)$ & $62 \%(54-68,72)$ \\
IIIB & $19 \%(16)$ & $9 \%(13)$ & $31 \%(19-44,49)$ \\
IV & $21 \%(18)$ & $13 \%(17)$ & $54 \%(34-70,84)$ \\
\hline
\end{tabular}

IASLC, International Association of the Study of Lung Cancer. *Estimated 5-year survival (95\% confidence interval, median survival time, months).

of excellence for patients with lung cancer that may provide a whole host of improved preoperative, intraoperative, and postoperative care. For example, consider just some of the preoperative factors that may have led to a greater survival: specialized chest radiologists to view metastatic lesions, the more liberal use of integrated PET/CT scans, more complete preoperative staging including better availability and/or expertise in EBUS and/or video-assisted mediastinoscopy, etc. These along with many other nonmeasured factors all conspire to favor a greater overall 5-year survival, and none have to do with the operative approach. Another important limitation to any series that has more than one surgeon is the difference in patient selection, pre-, intra-, and postoperative staging, surgical technique, and the differences in follow-up. Although these centers all use similar protocols for their patients, there may be and probably are subtle differences between the centers and surgeons. This affects the results at all stages of the process.

The strengths of this study include the fact that this was a consecutive series of patients and because most centers use robotics for more than $80 \%$ to $90 \%$ of their patients with lung cancer, patients were not highly selected. Patients were entered into prospective databases in major institutions that feature morbidity and mortality conferences that prevent underreporting of complications and mortalities. The intent to treat was used, and finally, inaccurate large administrative databases were not used for any data collection or comparison. Another strength is that $99 \%$ of the patients have current follow-up data and only $1 \%$ have been lost to follow-up.

In conclusion, this study represents the largest robotic series reported with the longest follow-up for patients with NSCLC. It shows outstanding stage-specific survival results that are at least comparable and, at this time of follow-up data, is superior to most other previous reports. However, continued follow-up of these patients is mandatory until all patients are 5 years out from resection. Finally, we should assess the true value of an operation or procedure for cancer not via just 30- and 90-day metrics but rather mid and long-term results of stage-specific survival.

\section{Conflicts of Interest Statement}

Dr Cerfolio is a consultant for Intuitive, C-SATS, Bovie, Ethicon, Covidien/Medtronic, Community Health Services, Davol/Bard, Myriad Genetics, KCI an Acelity Company, and Verb Medical. Dr Veronesi was a past proctor for a Medica. Dr Park is on the speakers' bureau for BardDavol and was a past proctor for Intuitive Surgical. Dr Dylewski is a consultant for Intuitive surgical, Ethicon, Verb medical, and Bard. All other authors have nothing to disclose with regard to commercial support.

\section{References}

1. Kent M, Wang T, Whyte R, Curran T, Flores R, Gangadharan S. Open, videoassisted thoracic surgery, and robotic lobectomy: review of a national database. Ann Thorac Surg. 2014;97:236-44.

2. Radkani P, Joshi D, Barot T, Williams RF. Robotic video-assisted thoracoscopic lung resection for lung tumors: a community tertiary care center experience over four years. Surg Endosc. 2015;30:619-24.

3. Kanagarajah P, Torres A, Bacigalupo A, Shaukat S, Myslicki LA, Williams R. Robotic video-assisted thoracoscopic lung resection: comparison of outcomes and learning curve from a single surgeon in a tertiary care center. In: C79. Multimodality approaches to diagnosis and treatment of lung cancer. Am J Respir Crit Care Med. 2016;193:A6022.

4. Lacroix V, Nezhad Z, Kahn D, Steyaert A, Poncelet A, Pieters T, et al. Pain, quality of life, and clinical outcomes after robotic lobectomy. Thorac Cardiovasc Surg. 2017;65:344-50.

5. Toker A, Özyurtkan MO, Kaba E, Ayalp K, Demirhan Ö, Uyumaz E. Robotic anatomic lung resections: the initial experience and description of learning in 102 cases. Surg Endosc. 2016;2:676-83.

6. Veronesi G. Robotic lobectomy and segmentectomy for lung cancer: results and operating technique. J Thorac Dis. 2015;7(suppl 2):S122-30.

7. Farivar AS, Cerfolio RJ, Vallières E, Knight AW, Bryant A, Lingala V, et al. Comparing robotic lung resection with thoracotomy and video-assisted thoracoscopic surgery cases entered into the Society of Thoracic Surgeons Database. Innov Technol Tech Cardiothorac Vasc Surg. 2014;9:10-5.

8. Rajaram R, Mohanty S, Bentrem DJ, Pavey ES, Odell DD, Bharat A, et al Nationwide assessment of robotic lobectomy for non-small cell lung cancer Ann Thorac Surg. 2017;103:1092-100.

9. Park BJ, Melfi F, Mussi A, Maisonneuve P, Spaggiari L, Da Silva RK, et al. Robotic lobectomy for non-small cell lung cancer (NSCLC): long-term oncologic results. J Thorac Cardiovasc Surg. 2012;143:383-9.

10. Allen MS, Blackmon S, Nochols FC, Cassivi SD, Shen KR, Wigle DA. Comparison of two national databases for general thoracic surgery. Ann Thorac Surg. 2015;100:1155-61

11. Park BJ, Flores RM, Rusch VW. Robotic assistance for video-assisted thoracic surgical lobectomy: technique and initial results. J Thorac Cardiovasc Surg. 2006;131:54-9.

12. Veronesi G, Galetta D, Maisonneuve P, Melfi F, Schmid RA, Borri A, et al Four-arm robotic lobectomy for the treatment of early-stage lung cancer J Thorac Cardiovasc Surg. 2010;140:19-25. 
13. Melfi FMA, Ambrogi MC, Lucchi M, Mussi A. Video robotic lobectomy. Multimed Man Cardio-Thorac Surg. 2005;2005:mmcts.2004.000448.

14. Thomas P, Doddoli C, Yena S, Thirion X, Sebag F, Fuentes P, et al. VATS is an adequate oncological operation for stage I non-small cell lung cancer. Eur J Cardiothorac Surg. 2002;21:1094-9.

15. Walker WS, Codispoti M, Soon SY, Stamenkovic S, Carnochan F, Pugh G. Longterm outcomes following VATS lobectomy for non-small cell bronchogenic carcinoma. Eur J Cardiothorac Surg. 2003;23:397-402.

16. Yildizeli B, Fadel E, Mussot S, Fabre D, Chataigner O, Dartevelle PG. Morbidity, mortality, and long-term survival after sleeve lobectomy for non-small cell lung cancer. Eur J Cardiothorac Surg. 2007;31:95-102.

17. Flores RM, Park BJ, Dycoco J, Aronova A, Hirth Y, Rizk NP, et al. Lobectomy by video-assisted thoracic surgery (VATS) versus thoracotomy for lung cancer. $J$ Thorac Cardiovasc Surg. 2009;138:11-8.

18. Lee PC, Nasar A, Port JL, Paul S, Stiles B, Chiu YL, et al. Long-term survival after lobectomy for non-small cell lung cancer by video-assisted thoracic surgery versus thoracotomy. Ann Thorac Surg. 2013;96:951-61.
19. Goldstraw P, Crowley J, Chansky K, Giroux DJ, Groome PA, Rami-Porta R, et al. The IASLC Lung Cancer Staging Project: proposals for the revision of the TNM Stage Groupings in the forthcoming (seventh) edition of the TNM Classification of malignant tumours. J Thorac Oncol. 2007; 2:706-14.

20. Flores RM, Ihekweazu UN, Rizk N, Dycoco J, Bains MS, Downey RJ, et al. Patterns of recurrence and incidence of second primary tumors after lobectomy by means of video-assisted thoracoscopic surgery (VATS) versus thoracotomy for lung cancer. J Thorac Cardiovasc Surg. 2011; 141:59-64.

21. Wilson JL, Louie BE, Cerfolio RJ, Park BJ, Vallières E, Aye RW, et al. The prevalence of nodal upstaging during robotic lung resection in early stage non-small cell lung cancer. Ann Thorac Surg. 2014;97:1901-7.

Key Words: lung cancer, quality outcomes, robotic surgery, survival 